\title{
A Descriptive Analysis of Economic Indicators
}

\author{
Ronald A. Ratti
}

E publishes a series of economic indicatom, the most widely followed of which are the composite indexes of leading, coincident and lagging indicators.' The significance attached to these series is attested to by the promptness with which their month-to-month movements are reported and analyzed by the news media." Economic agents monitor the behavior of these indexes because, historically, they have been thought to provide useful information on current and future changes in the economy.

The objective of this paper is to describe how these indexes are constructed and revised, to provide a descriptive explanation for why they might provide information on future economic conditions, and to examine critically their usefulness. ${ }^{+}$In the final section of

Ronald A. Ratti, associate protessor of economics, University of Missouri-Columbia, is a visiting scholar at the Federal Reserve Bank of St. Louis. Laura Prives and John G. Schute provided research assistance. Published monthy in Business Conditions Digest by the U.S. De-
partment of Commerce.

2For example, an estimate of the behavior of the Index of Leading Indicators for August 1984 was released by the Department of Commerce on September 28. That same day, the New York Times carried a lengthy article with the headine "Economic Index Up by $0.5 \%$ " (Hershey [1984]). United Press International (1984) carried a story headed "indicators Pise Slighty in August." On October 1, the Christian Science Monitor carried stories focusing on the behavior of the leading index for August 1984 (Cook [1984] and Nenneman [1984]), and The Wall Street Joumal ran a story headed "Economic Index Eases Worries Over Slowdown" (Murray [1984]).

For an authoritative discussion of the use of composite indicators for forecasting, see Zarnowitz and Moore (1982). On the use of the leading series for forecasting, see Hymans (1973). Stekler and Schepsman (1973) and Neftci (1979). For a summary of work on the use of the index of leading indicators for forecasting, see Gorton (1982).

"This work draws on the following basic sources: Zamowtz and Boschan (1975a, 1975b), Moore (1984) and Zarnowitz and Moore (1982). the paper, the difficulties inherent in using the index of leading indicators as a forecaster of future economic conditions are discussed. Emphasis is placed on the leading indicator index since it is the most widely reported and well known of the indexes considered.

\section{A D P

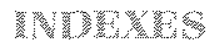

Individual and composite indicators are used to predict downtums and uptums in the economy and to monitor the degree of strength or weakness in a recession or recovery. Analysts generally acknowledge that in order for individual indicators to provide useful information they should have the following character istics: (1) they should represent and accurately measure important economic variables or processes; (2) they should bear a consistent relationship over time with business cycle movements and tuns; $(3)$ they should not be dominated by irregular and non-cyclical movements; and 44 they should be promptly and frequently reported." These requirements ensure that the best indicators regularly provide timely economic information on the stages of the business cycle.

On the basis of these criteria, the Bureau of Eco+ nomic Analysis has evaluated, and continues to evaluate, hundreds of economic time series. Only those series with a good overall performance that are avail-

\footnotetext{
Hi a series did not bear a consistent felationship over time with the business cycle, it woutd not be usetul as an indicator of business cycle conditions. If a series was dominated by non-cyclical factors, it would not be possible to "read" cyclical developments from the behavior of the series. A series should be promptly and regularly reported in order to provide a steady stream of timely information. For a demonstration of the formal application of the criteria used for evaluating the usefuness of economic series as indicators, see Zarnowitz and Boschan (1975a).
} 
able monthly with a short time lag and are not subject to large revisions are candidates for inclusion in the three major composite indexes.

The composite indexes of leading, coincident and lagging cyelical indicators each measure the average behavior of series showing similar leading, coincident and lagging timing at business cycle tums. Components of the indexes are also chosen so as to represent as broad an array of diverse activities and sectors as possible. This requirement is meant to ensure that the composite indicators continue to monitor and closely shadow economic activity, even if the causes and nature of cyclical change vary over time and the performances of some individual indicators deteriorate. since each business cycle has unique characteristics, individual series can be expected to perform better during some cycles than others. Without prior information on the causes of current economic change, if seems best to rely for information on groupings of series rather than individual series.

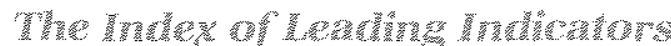

Table 1 lists the components of the three composite indexes. The leading index consists of individual components that might lead measures of economic activity." For example, housing starts, new incorporations, contracts for construction and new orders for machinery and equipment are leading indicators, since they represent early commitments to future economic activity.

The inclusion of some other components in the leading index is less obvious and move involved. This is partly because there is no single well-developed theory linking each of the indicators to the business cycle. The economic series that make up the composite indicators are included primarily because they perform well statistically in relation to the cycle, not because they are the operational counterparts of variables in an economic theory of business cycles.

There is usually some economic rationale, however, for including each series in the index. An increase in average weekly hours worked, for instance, presumably leads the business cycle since it is easier for employers to move to higher output levels in the initial stages of an expansion by increasing the utilization of

EA discussion of why the components of the index of Leading Indicators lead the economy is provided in Moore (1984), chapter 21. A detailed discussion of the relative strengths of the components of the Index of Leading Indicators is given in Zarnowitz and Boschan (1975a). labor than by increasing the number of employees.

The remaining components of the index of leading indicators and the rationale for including them in the index are the following: Initial claims for unemployment insurance represent first claims filed by workers newly unemployed or claims for subsequent periods of unemployment. Slower deliveries, which inversely reflect the volume of business of firms supplying purchasing agents in the Greater Chicago area has been found to precede changes in the actual volume of business. The sum of changes in inventories on hand and on order are assumed to reflect changes in the desired stock of inventories. The desired stock of inventories is assumed to rise if the anticipated level of sales increases.

"Change in sensitive materials prices, smoothed" is based on indexes of crude and intermediate materials prices and spot market prices of raw industrial materials. Movements in these prices are assumed to reflect variations in demand relative to supply in the process of building up or drawing down raw material inventories. A rise in prices is taken to indicate increased demand for the output of the manufacturing and construction sectors. Stock price movements affect and measure the general state of business expectations about future profits. When prospects for profits deteriorate, investment plans are shelved and expansionary business operations are contracted.

The inclusion of money and credit indicators capture the impact of changes in real balances and the availability of credit on future activity. During the late stages of a boom, bank deposit creation is limited by the availability of reserves, and the rate of increase in consumer prices begins to accelerate. The opposite is true during a downturn. These effects cause the turning points in the rate of change in real $\mathrm{M} 2$ to lead the turning points in the business cycle. The change in business and consumer credit also is a leading indicator, since many economic actions require financial arrangements before their inception.

\section{The Ind}

The components of the Index of Coincident Indicators are measures of aggregate economic activity in the areas of employment, real income, production and

\footnotetext{
This is an ad hoc statistical criterion that seems in contrast to the "economic" reasoning behind other components. The use of this indicator is being questioned on the grounds that faster delveries reflect better management rather than slack demand, especially in light of increasing computerization.
} 


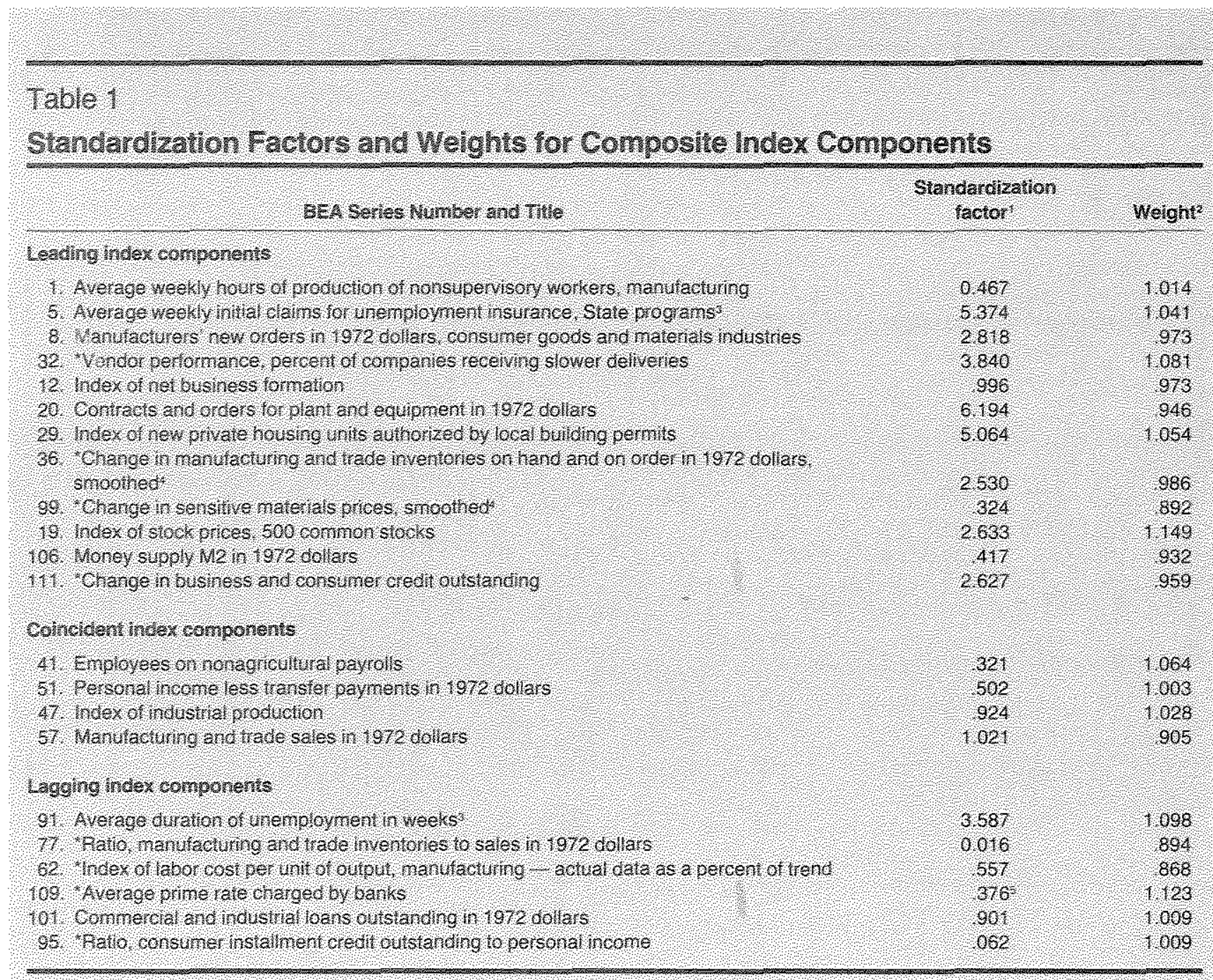

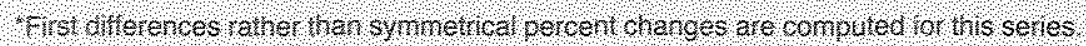

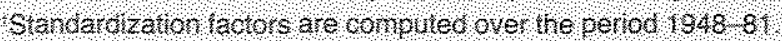

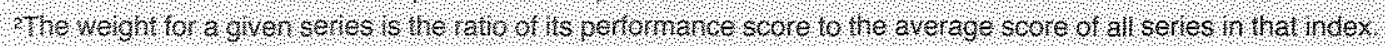

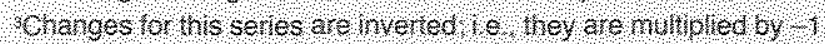

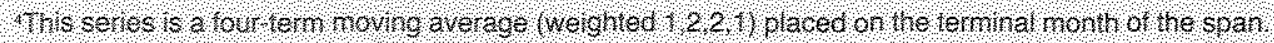

This slandardzation actols conpuled over the period 196681

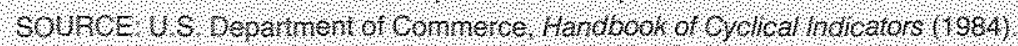

tr

real sabs. The hadex of Conctum indicatom, wogeher whin oher comoiden indicanors, show how wel the gconom is farthe and is used bidentiv and date the peaks and rough in the buspess cycle. Thes identhotion and dating, however, can only be done aher the hrming ponts have gcemed.

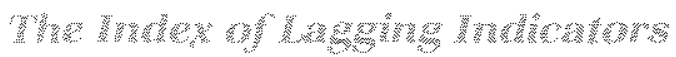

The index of lagging molicators is designed to contm both downtums and uphums in bushess ac- wver lagging indicators can also be useful for forecastmg purposes, because their turns sometmes lead the opposite turns of the leaching indicators. Eagging indicators, such as bank interest rates, unit habo costs, inentory holdings and outsuding debt an associnted win the costs of dong business. Peduclons in these itens during a recession lav the basis for the subsequen upum, as well as having an enhanoing effect on such leading indicators as comminments so invest, inventory accumulation and new chedit outstanding. 
Table 2

Index Standardization and Trend Adjustment Factors: $1948-81$

\begin{tabular}{|c|c|c|c|c|}
\hline Composite iriter & 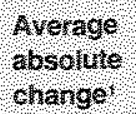 & $\begin{array}{l}\text { standardization } \\
\text { actort }\end{array}$ & 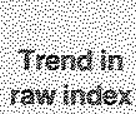 & 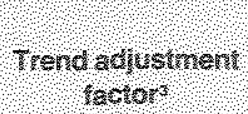 \\
\hline leading ndex & 0496 & 0582 & $0,32 \%$ & $1008 \%$ \\
\hline Goncidentindex & $\checkmark 85$ & 1000 & 486 & 147 \\
\hline Lagging nidex & 602 & $\$$ & 253 & +08 \\
\hline
\end{tabular}

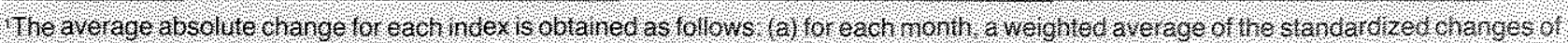

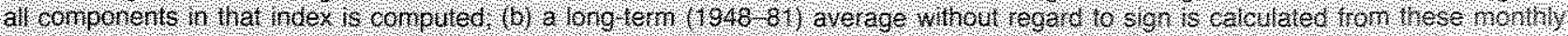
averages.

This neasure is the ratio of the average absolute change th each mdex to the average absolute change h the conciden index

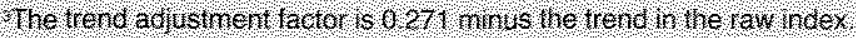

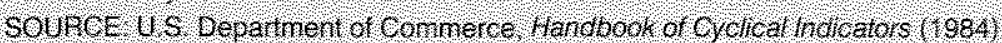

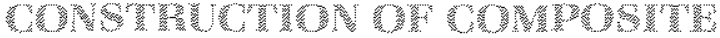

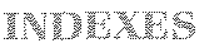

Construetion of the composite indexes involves several statistical operations on boh the indiviual data series that make up the indexes and on the indexes themselves. These steps are described in this section. The accompanying insert provides and lllustation of how the indexes are constructed.

The forst step in constucting the composine indexes involves standarding the indwhal series. Standay ization prevents the relatively volatile seres from dominathg movenents in the composine index. If tor example, a series rypicaly exhibiss lange pewenage changes, a fance to standarize woud cause this series to stamp the effects of series that ypically change by more modest anounts.

For each indidual series, the monh-ho-month porcentage change is calculated. For series aready in perentage form or in ratio form the nonth-10-monh diference is laken. The percentage changes in a componen series are then standardized by diving them by the long-run average percentage change in that serios without regard to sign the standardzation facton." These standadizaton factors are shown in table 1

\footnotetext{
The sum of the percentage changes of even a highly volatile series might be zero if large negative values are just as lkely bo be lolowed by large positive values as more negative values. For this reason. the sum of the absolute values of the percentage changes is used as a measure of volatity. This means that the standardization factor of a series that alternates ir value between +1 and -1 is the same as the standardization fector of a series that has values of only +1
}

A composite index is consuncted by weighth the standardized changes of its components. The wegh assigned each component is detemmed by the overall scomeach seves weeves on the basis of anumer of economic and statistical criteria. The aphicaton of These criteria involves both objective and subjective evaluations of such factors as oommic sinnicance vimely reognition at business cre turning ponts. dogree of conformity to the stages of the business

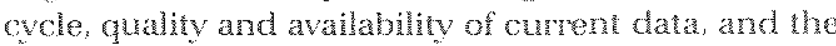
importance of non-cvelual movenents in the series:"

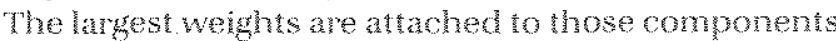
with he bes overal peromance on the basis ar these criterin. The wernh ahahed to the componens of he composite indexes are shown in thine As can be

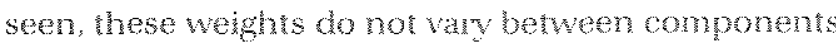

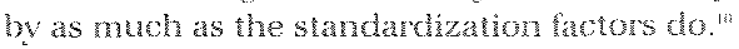

The raw powentage changes in the leading ard layging indexes, grven by the sum of the wrighed sundendized percenage changes of heir components. are then abusted so as 10 fachitate comparison wh the conciden index. This is done by equang the

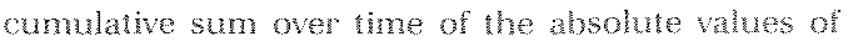
changes in the leadmg and lagying indox wh the sum of the absolute whuses of thanges in the commentm index. The index sardardizaton froton based on data over $1948-81$ mpear in tabe 2

For a delaled explanation of the phincios upon whoth the sconing system is based, see Zamowtz and Boshan (1975a) and U.S. Deparment of Commerce $(1984)$.

Averbach (1982) has argued that a simple average woighing scheme yields a leading composite index that is very smilar to the official leading index and that elaborate procedures for teterming weights are therefore unnecesseny. 


\section{Construction of Composite Indexes: An Example}

The jorocaltres for constructing eomposite in dexes from the basic monthly data seties are illis: trated in the example below In the example the prelininary estimates of the leading coincident and lagging indicators are calculated for June 1084 . The data, taken from the July 1984 issue of business Conditions Digest, are presented in the table on the opposite page

Note that data on several components change m inventonies business and consumer credit manwacking and tride sales, he tatio of manufactir: ing and trade inventovies to sales, and the ratio of consumer installinent rredit outstanding 10 per sonal ineome - were not avallable these omis. sions and subsequent revisions in the original data will be sources of change in successive estimates of the three indexes:

The cohmm headed weighred and stanlardized percentage change' is oblamed by dividing the percentage change in each component by its standardization factor, then muluplvine by its weight both or which are presented in table 1 and explained in the text The sum of the numbers in this column provide estimates of the moventents during June in each of the indexes that have not yet been standardized for compatibility aeross the three indexes: or detrended for the leading, comcident and lag: ging mdicators these figures are $-0.777,0.888$ and 0.398 percent, respectively Diwiding each of thost numbers by the index standardization faerors and then adding the rend factors bouk of which are given in table 2 , yields the following preliminaty estimates of the changes in the Niree indexes for June:

Percentage change $\mathrm{n}$

$$
\begin{aligned}
& \text { Leading Index }=-10.5770 .582+1.139=-0.9 \\
& \text { Coincident Index }=10888 / 1000 \% \text { 175 }=07 \text {. } \\
& \text { lageing lndex }=0.398 / 0.707 t+018=0.6
\end{aligned}
$$

The numbers are also divded by the sum of the welohts on the components induded han index. These sums are 100053095 and 4.098 tor the a vartable components of the leadng comcident end agging ndexes, espectively.
In addition, a trend adjustment procedure is used to make the trends in the three major composite indexes equal to the average of the trends in the components of the coincident index. This is done by subtracting the trends in the leading, coincident and lagging indexes $10.132,0.446$ and 0.253 , respectively and adding in the average of the monthly trends in the components of the coincident indexes $(0.271)^{\prime \prime}$ The trend adjustment facilitates the use of the three indexes as indicators of levels of activity. The trend adjustment factors are listed in table 2 .

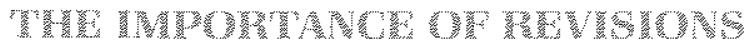

A preliminary estimate of the performance of the composite indexes for a given month appears loward the end of the following month. The July issue of Business Conditions Digest, for example, carries a pre-

\footnotetext{
Details on trend adjustment can be obtained from U.S. Department of Commerce (1984).
}

liminary estimate of the composite indexes in June The August issue of Business Conditions Digest will then carry a revised estimate of the June indexes. The second estimate typically differs from the first because data on some series were not originally available and because data that were originally available have been updated.

The net effect of these revisions is often a significant change in the estimate of the performance of the composite indicators. Table 3 illustrates that the absolute size of the first revision in the indexes of leading, coincident and lagging indicators averaged about $0.5,0.3$ and 0.3 percentage points, respectively, for the first nine months of 1984. These revisions appear to be substantial, giver that the preliminary estimates of the monthly changes in these indexes have avemge absolute values of only about $0.7,0.7$ and 1.0 percentage points.

The sources of revisions in the three indexes vary from one month to the next. It appears, however, that for the monthly estimates during 1984 the subsequent availability of data on series not available initially ac- 


\section{Construction of Composite Indexes: An Illustration}

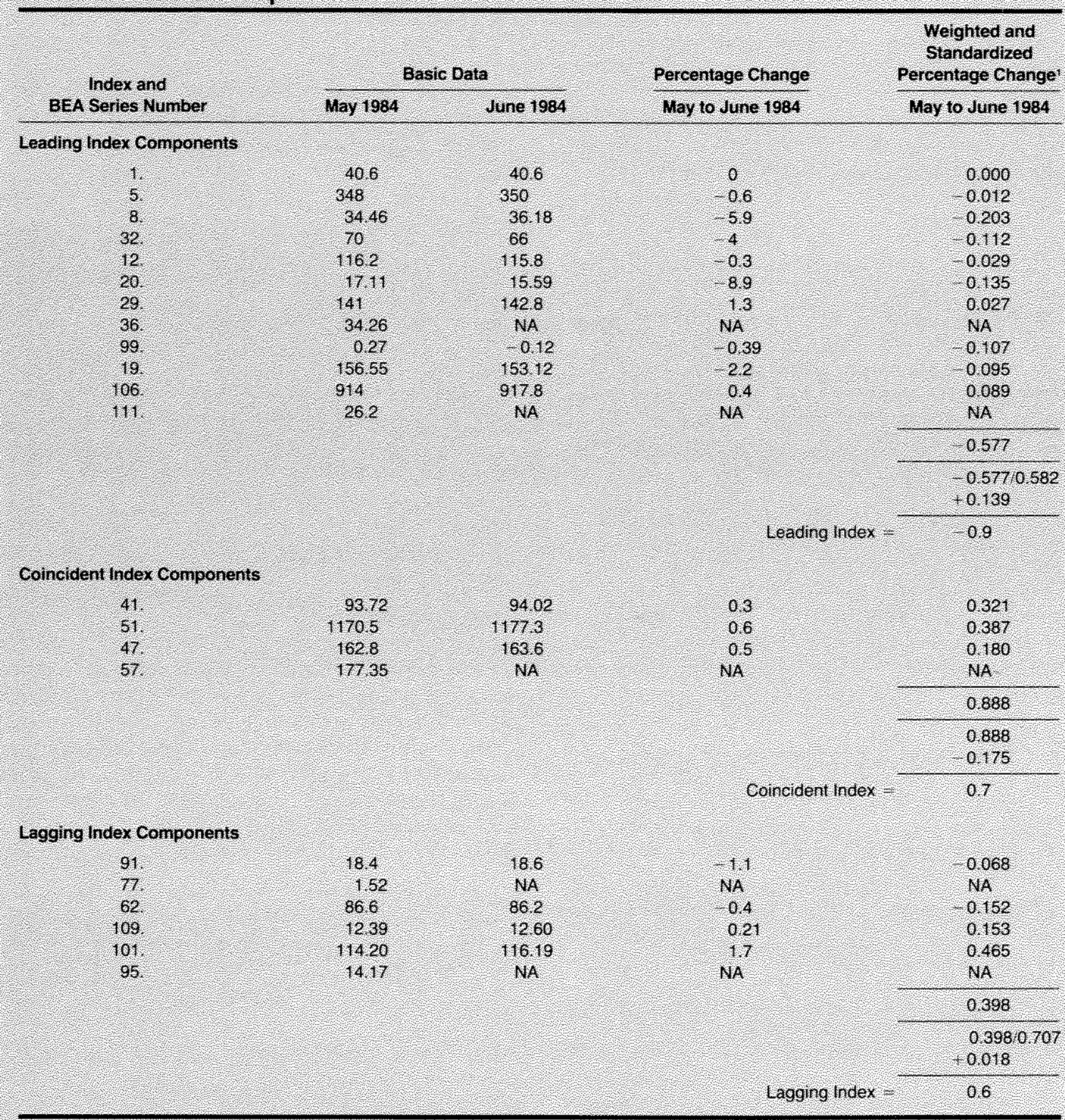

Percentage change in component series is dWded by the relevant standar ozation tactors and nulliplied by the relevant weight given in tables 1 and 2

NA not avaliable

SOUnCE US Deparinen or Commerce. Bushess Conditons Digest (July 1984 ) 


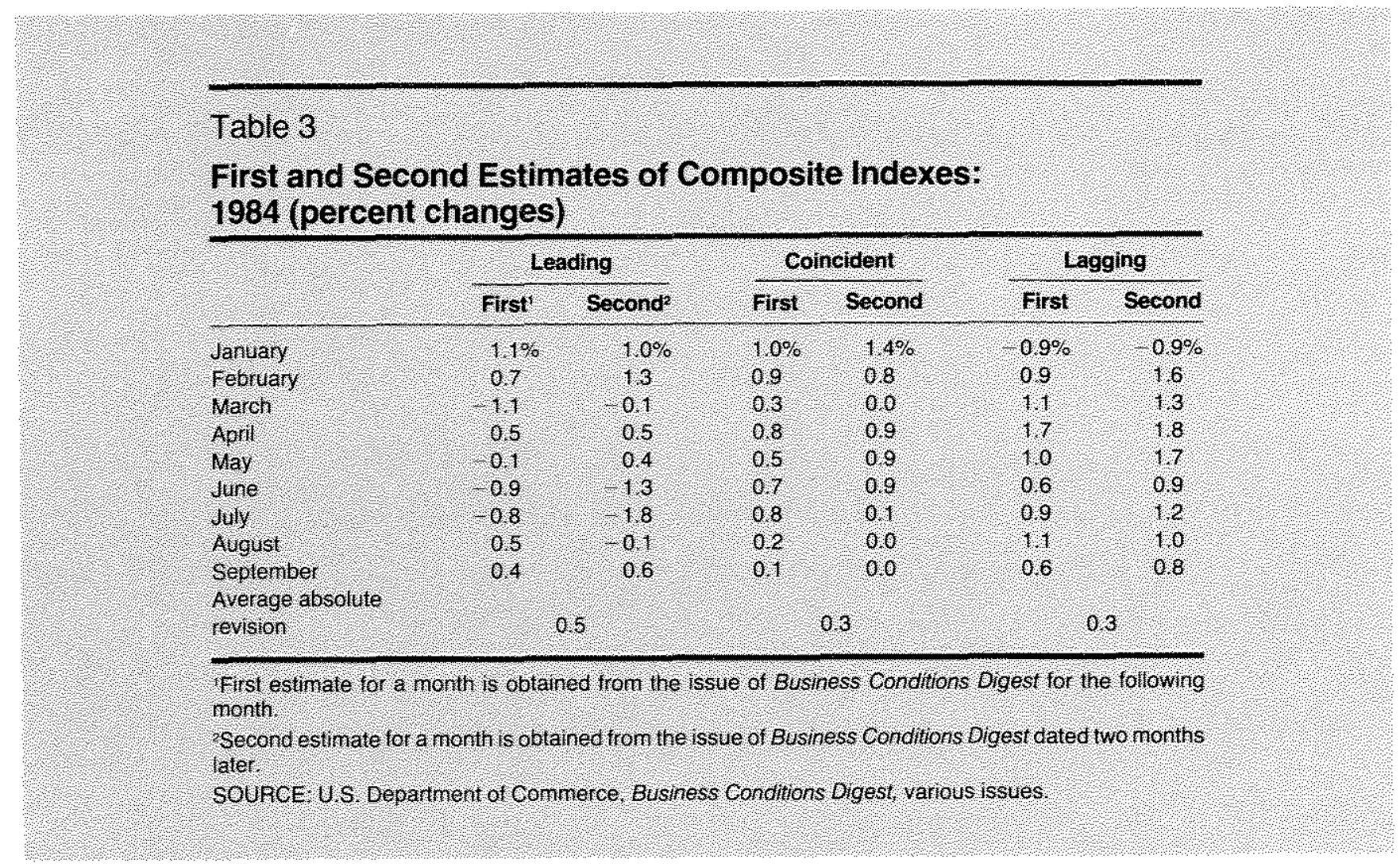

counts, on the average, for over two-thirds of the first revision in leading and lagging indexes and about onekalf of the revision in the coincident index. The balance of the revisions are due to updated estimates of data that were avalable for the initial estimates.:

Estimates of the composite indexes are subject to revision for a period of 12 months. The first and last

\footnotetext{
:2These observations are based on the following analysis. Let the first and second estimates of the rate of change in a composite index be $x_{11}$ and $x_{21}$. The revision is given by $x_{1}=x_{21}-x_{1}$. The portion of the revision due to the updating of data series available for constructing $x_{t+}$ can be calculated by estimating the change in the composite indexes assuming the continued nonavailability of data on series not originally available. If this estimate of the change in the composite indexes is denoted by $e_{\text {, }}$, the revision in the composite indexes due to updating data is given by $u_{t}=e_{t}-x_{1}$. The portion of the revision in the behavior of the composite indexes due to using data on series not avaliable for the initial estimate is given by $a_{t}=x_{2 t}-e_{1}\left(=r_{1}-u\right)$. The relative contributions of updated data and increased data availability are defined to be$$
u=\left(\Sigma_{i} u_{+}\left(\text {sign of } r_{t}\right)\right) /\left(\Sigma_{i}, r_{i}\right)
$$

and$$
a=\left(\Sigma, a_{1}(\operatorname{sign} \text { of } r)\right) /\left(\Sigma_{t}\left|r_{t}\right|\right) \text {, }
$$

respectively. Clearly $u+a=1$. For the new composite indexes defined in table $1, u=.7,6$ and .9 for the leading. coincident and lagging indexes for the period January 1984 to July 1984 . Revistons seem to be mostly due to the use in later estimates of intially unavailable data, at least over the time period considered and for differences between the first and second estimates of the indexes.
}

available estimates of the leading indicator from 1979 to 1983 appear in chart 1 . As we can see, these estimates sometimes diverge by substantial amounts. In table 4 , the average absolute values of successive revisions in estimates of changes in each composite indicator from 1979 to 1983 are presented. For purposes of comparison, the table also includes the average absolute value of selected estimates of the percentage change in each index. The average absolute value of the first revision the difference between the first and second estimates in the leading indicator is calculated to be 0.4 , and the average absolute value of revisions subsequent to the first revision the difference between the final and second estimates in the leading indicator is found to be 0.5 . Since the average absolute vatue of the total revision the difference between the final and first estimates in the leading indicator $\{0.61$ is less than the sum of the individual revisions 10.9 , it is apparent that successive revisions sometimes overshoot the final estimate. Given that the final estimates of the leading, coincident and lagging indicators have average absolute values of ony $1.0,0.7$ and 0.9 , respectively, errors in early estimates would seem to be substantial.

The difficulty created by error in early estimates can be illustrated by considering recent months during 1984. Fom table 3 , it can be seen that the first estimate 
Chan I

First and Final Estimates of Leading Index

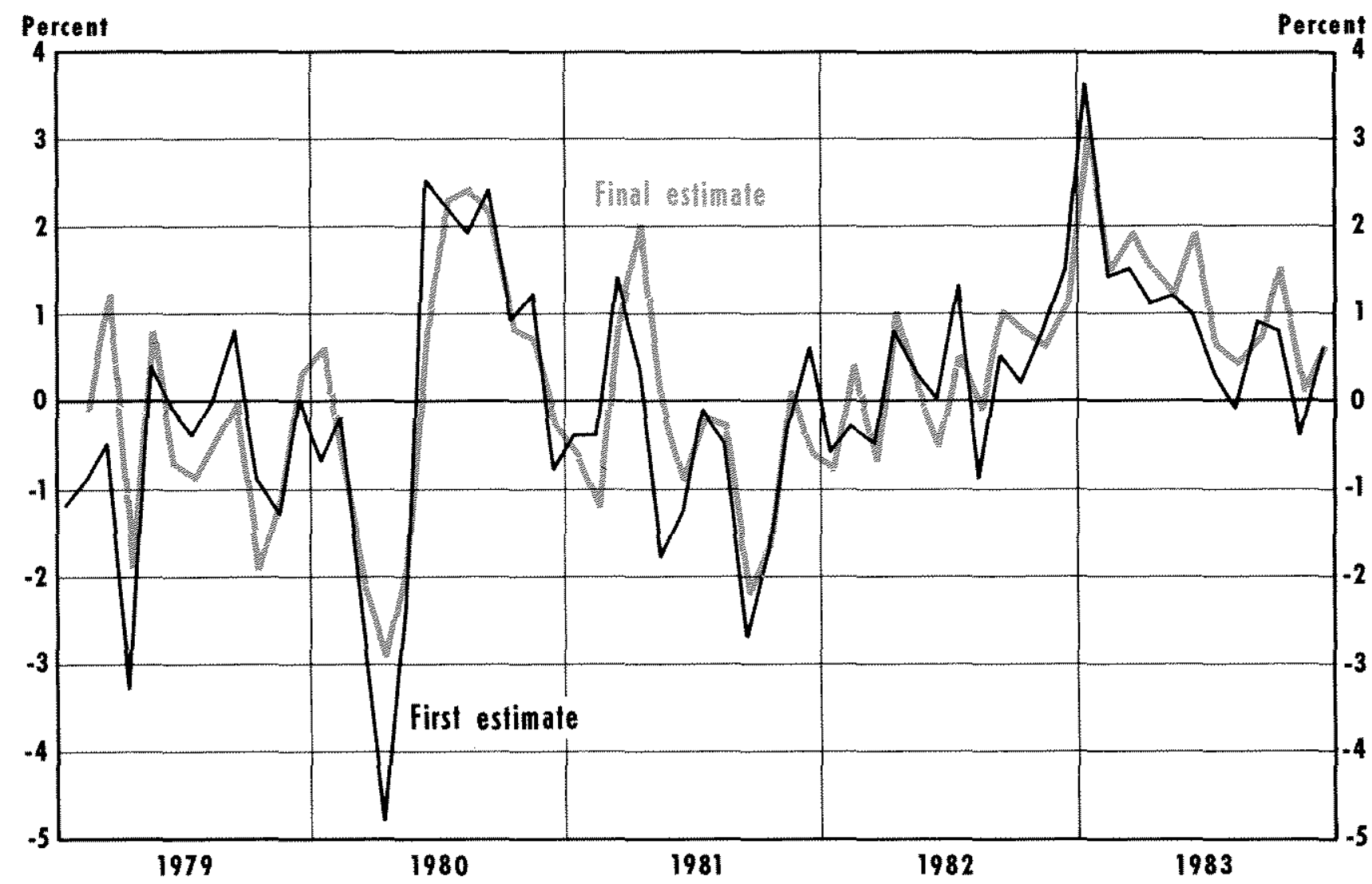

Table 4

Average Absolute Values of Estimates and Revisions of Composite Indicators: $1979-83$

\begin{tabular}{|c|c|c|c|}
\hline & Leading & Coincident & Lagging \\
\hline Fist estimale? & 111 & 07 & 2.5 \\
\hline Second estrinate & 1) & 07 & 10 \\
\hline Final estinate. & 10 & 07 & 09 \\
\hline Fistrevisioll & 04 & 0.4 & 08 \\
\hline Revisions subsequent lo itst revision & 0.6 & 0.2 & 1,2 \\
\hline Fevsion from lirst to linal estirnates? & 0.6 & 044 & 19 \\
\hline
\end{tabular}

SOURCE US. Department of Commerce, Business Conditons Digest, various issues. 
of the percentage change in the leading indicator in May was negative. The second and subsequent (not shown estimates for May are positive. The first and subsequent estimates for June and July las of the middle of December) are negative. This makes the behavior of the index during August of some interest. For August, the first estimate was positive $(+0.5)$, the second negative $\{-0.1\}$, and the third lavailable in November) positive $(+0.1)$. A further illustration of the difficulties created for forecasting is taken up in the next section.

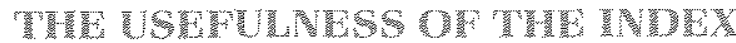 OP

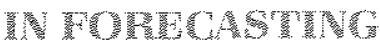

One way of evaluating the index of leading indicators is to examine its ability to predict the onset of a recovery or a recession. This is usually done by observing the number of consecutive monthly declines or increases in the index." If the index has been rising steadily and the economy has been expanding, a fall in the index for several months heralds a recession. likewise, if the index has been falling for several months and the economy has been depressed, a rise in the index over several months heralds a recovery.

This approach to forecasting the business cycle begins by specifying the number of successive months of reversal in the index's behavior necessary to predict a turning point in the cycle. In general, the method is more reliable the greater the number of consecutive months of decline or increase required to forecast a turning point. When the lead time in the forecast is increased, however, it reduces the number of cansecutive months of reversal required to make a forecast.

Using both two and three months of consecutive movement in the index as a criteria for prediction, Wood (1984) has reported the reliability and lead time of using the leading index to forecast turning points in the economy's late of growth. His observations are reported in table 5 .

\footnotetext{
${ }^{+3}$ For a discussion of an alternative criteria for forecasting tuming points, see Zarnowitz and Moore (1982). Work by Zamowitz and Boschan (1975b) suggests that the ratio of the concident indicator to the lagging indicator would be a useful predictor of turning points. Moore (1969) first suggested the use of the ratio of the coincident to lagging indicators for forecasting purposes. For a history of the basic idea that lagging indicators might lead, see Moore (1984), chapter 23
}

These data reveal that the index of leading indicators has forecasted every recession and growth recession (which occurs when the rate of growth in the economy slows down/ since 1948."A negative number indicates the number of months by which either a two- or three-month rule leads a peak or trough in the rate of growth. A positive number indicates the number of months by which the use of the rule lagged behind a turning point. For example, since the leading indicator declined for several months starting in August 1948 , two and three-month declines in the indicator lead the growth cycle peak in November 1948 by one and zero months, respectively.

Use of a two-month rule for forecasting a glowth cycle peak gives a longer lead time than the threemonth rule by more than one month for the recessions starting in both December 1969 and January 1980. 'This means that there were isolated consecutive monthly declines in the index in February and March 1969 and in November and December 1978, that is, declines that were not immediately followed by recession.

The lead times in table 5 refer to the forecasting performance of the final estimates of the leading indicator. In general the final estimates are not the same as the initial estimates. These differences between ealy and final estimates of the indexes can sometimes create serious problems in forecasting turning points in the growth cycle. For example, table 5 indicates that three consecutive monthly declines in the leading indicator forecasted the onset of the 1980 recession by five months. These declines in the final estimate of the leading indicator, which occurred during June, July and August 1979 , are shown in table 6 . The problem with this analysis from a forecasting viewpoint is that the first and second estimates of the leading indicator fid not register declines for August. The second estimate for August 1979, which became available at the end of October 1979, showed a positive rise in the leading indicator of 0.1 percent. As this example illus-

\footnotetext{
${ }^{14} \mathrm{~A}$ growth cycle is a fluctuation around the long-run trend in economic growth. Most business cycles contain, and coincide with, one growth cycle. The business cycle starting at the end of 1948 contaned two growth cycles. The dates in table 5 indicate that economic growth slowed down from March 1951 to July 1952, then picked up again to peak in July 1953, at which time a recession began. The very tong business cycle starting during 1960 contained three growth cycles, with slowdowns in growth starting immediately after May 1962 and June 1966, and upturns in growth starting in October 1964 and October 1967. A recession did not begin until December 1969. For a discussion of the concept of growth cycles. see Moore (1984), chapter 5.
} 


\section{Table 5}

Ex Ante Timing of the Leading Indicators During Growth Cycle Turning Points: 1948-82

\begin{tabular}{|c|c|c|c|c|c|}
\hline $\begin{array}{l}\text { Growith } \\
\text { Gycle } \\
\text { Peaks }\end{array}$ & 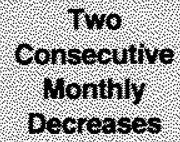 & $\begin{array}{l}\text { Thres. } \\
\text { conseovitye } \\
\text { nominy. } \\
\text { Decreases. }\end{array}$ & $\begin{array}{l}\text { Growth } \\
\text { Grocle } \\
\text { Trough }\end{array}$ & 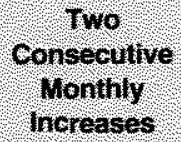 & $\begin{array}{l}\text { Three } \\
\text { consecuive } \\
\text { monthly } \\
\text { Inoreases }\end{array}$ \\
\hline
\end{tabular}

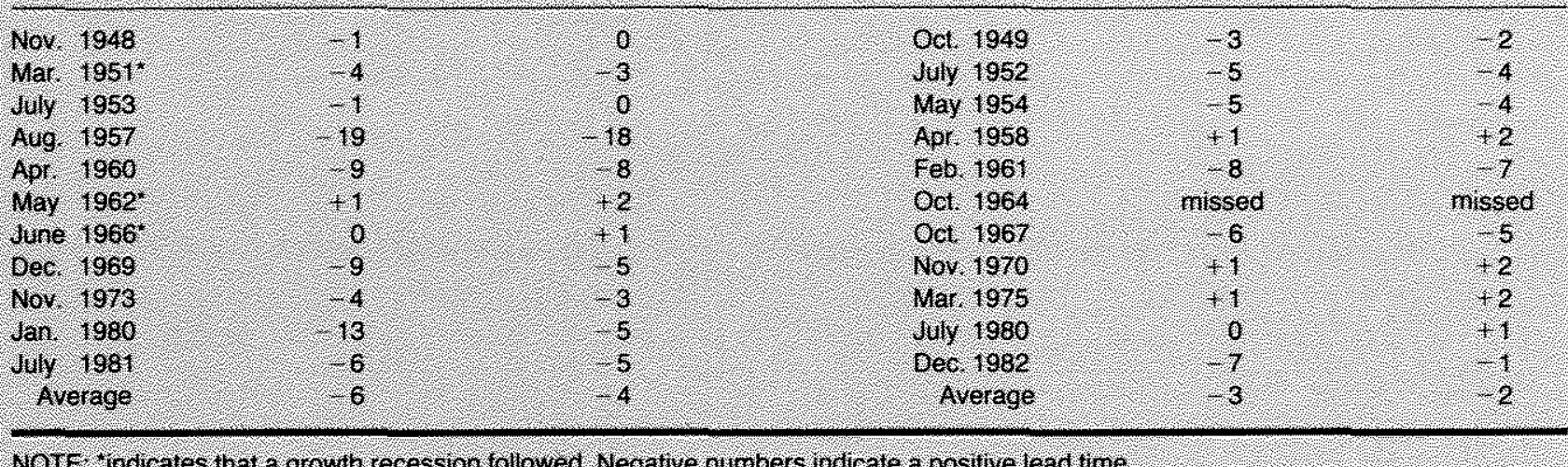

NOTE, indicates that a growh recession followed. Negatwe numbers ndicate a positve lead time

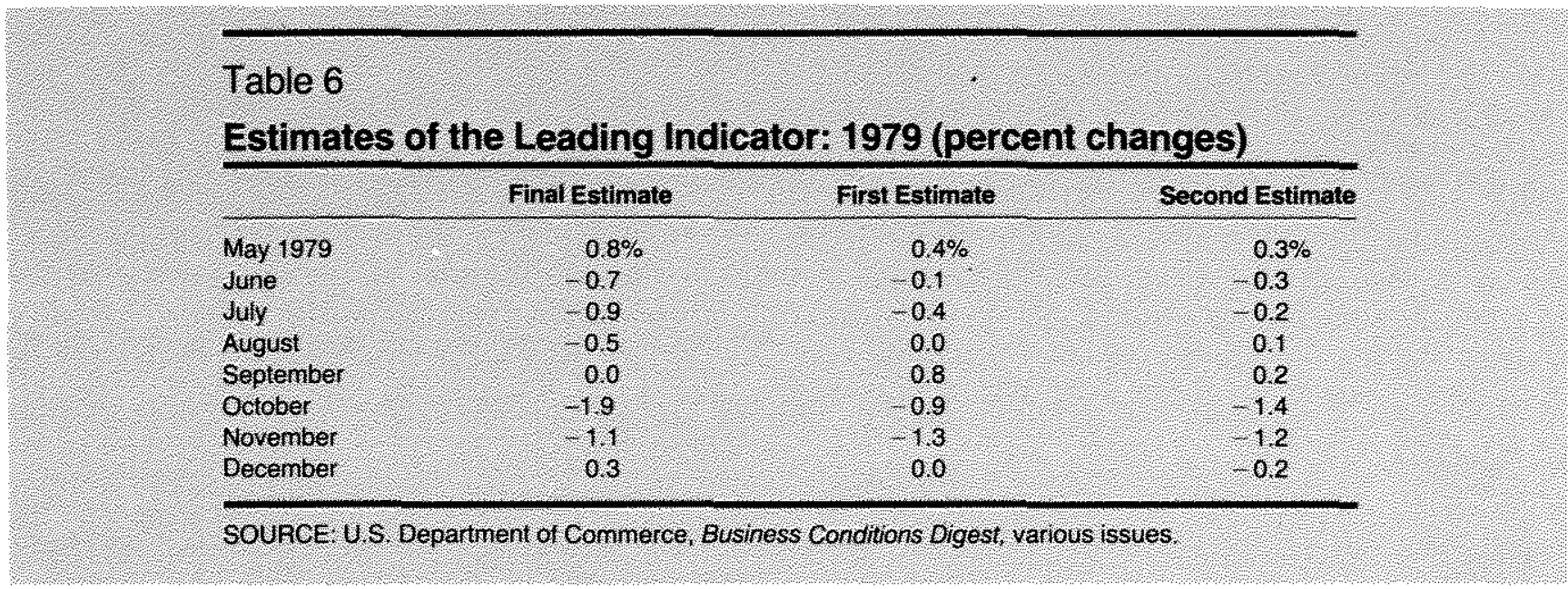

trates, the likely magnitude of revisions in preliminary estimates of change in the composite indexes complicates the interpretation of signals in the short run.

Additional qualifications also need to be made concerning the forecasting ability of the index of leading indicators: $:^{\text {: }}$

(1) The leading index has falsely forecasted the onset of recession on at least three occasions. The index

\footnotetext{
${ }^{15}$ These reservations also apply generally to the use of the ratios of the leading to coincident and coincident to lagging indexes that have also been suggested as predictors of economic activity
}

declined for three consecutive months in late 1960 and a recession didn't start until 17 months later. The index fell for two consecutive months in mid 1963 and mid-1971 and recessions did not begin until two or three years later.

(2) There is no clear a priori criteria as to whether declines in the index forecast a full-blown recession or merely a significant slowing in the economy. Consecutive monthly declines in the index preceded slowdowns, but not recessions, in economic growth in 1951,1962 and 1966.

(3) The lead times by which the leading indicator predicts a tuming point are highly variable. Indeed, 
the three monthly declnes in the index in Decembet 1955, January and February 1956 were so far ahead of the business cycle peak that occurred in August 1957 that they can almost be regarded as a false signal. Given the historical tendency of the U.S. economy to exhibit cyclical fluctuations, a recession eventually will follow a decline for any other movement for that matter) in the indicator. In order for the indicator to be a really useful forecaster, it also would need to forecast the timing of a recession within narrower bounds than it has since 1948 .

(4) By using the most up-to-date version of the index, a favorable bias is introduced into this evaluation of the predictive performance of the leading indicator. The components of the index and the standardization, weighting and trend factors have been altered continually through the years. Currently, thev are based on data from 1948-81. The current index has been designed so as to obtain as favorable an ex post record as possible. While this is the appropriate means for constructing an index that will lead future economic activity as veliably as possible, the application of the current index to historical business cycle data does not measure the forecasting performance of the leading indicator actually in use when the forecasts were made.

In summary, the usefulness of the index of leading economic indicators for forecasting would seem to be seriously circumscribed by the problem of the highly variable lags by which economic activity follows the index, and by the large revisions by which initial estimates of the index are adjusted.

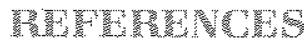

Auerbach, Alan J. "The Index of Leading Indicators: "Measurement without Theory. 'Thirly-five Years Later," The Review of Economics and Statistics (November 1982), pp. 589-95.
Cook, David T. "Fed Meets This Week Amid Fresh Signs of Slower Economy," Christian Science Monitor, October 1, 1984.

Gorton, Gary. "Forecasting with the Index of Leading Indicators," Federal Reserve Bank of Philadelphia Business Review (Novem" ber/December 1982), pp. 15-27.

Hershey, Robert D. Jr. "Economic Index Up by $0.5 \%$," New York Times, September 29, 1984.

Hymans, Saul $H$. "On the Use of Leading Indicators to Predict Cyclical Turning Points," Brookings Papers on Economic Acfivity (February 1973), pp. 339-84.

Moore, Geoffrey H. "Generating Leading Indicators From Lagging Indicators," Western Economic Joumal (June 1969), pp. 135-44.

Business Cycles, Inflation and Forecasting, National Bureau of Economic Research Studies in Business Cycles No. 24 2nd ed. (Ballinger Publishing Company, 1984).

Murray, Alan. "Economic Index Eases Worries Over Slowdown," The Wall Street Journal, October 1, 1984

Neftci, Salih N. "Lead-Lag Relations, Exogeneity and Prediction of Economic Time Series," Econometrica (January 1979), pp. 10113.

Nenneman, Richard A, "Latest Economic Data, Dip in the Prime Rate Look Good for the Economy," Christian Science Monitor. October 1, 1984 .

Stekler, H. O., and Martin Schepsman. "Forecasting With An Index of Leading Series." Joumal of the American Statistical Association (June 1973), pp. 291-96.

United Press International. "Indicators Rise Slightly in August," N.Y. Joumal of Commerce, October 1, 1984.

U.S. Department of Commerce. Business Conditions Digest, varous issues.

Handbook of Cycical Indicators, 1984.

Wood, Steven A. "The Index of Leading Indicators: What is it Telling Us?" Chase Econometrics (September 1984), pp. A.24-A.33.

Zarnowitz, Victor, and Chartotte Boschan. "Cyclical Indicators: An Evaluation and New Indices." Business Conditions Digest (U.S. Department of Commerce, May 1975), pp. V-XIX.

"New Composite Indexes of Coincident and Lagging Indicators," Business Conditions Digest (U.S. Department of Com. merce, November 1984), pp. $\vee-X \times 1$.

Zarnowitz, Victor, and Geoffrey H. Moore. "Sequential Signals of Recession and Recovery," Joumal of Business (January 1982). 